\title{
laboratorios de investigación, en Pensilvania
}

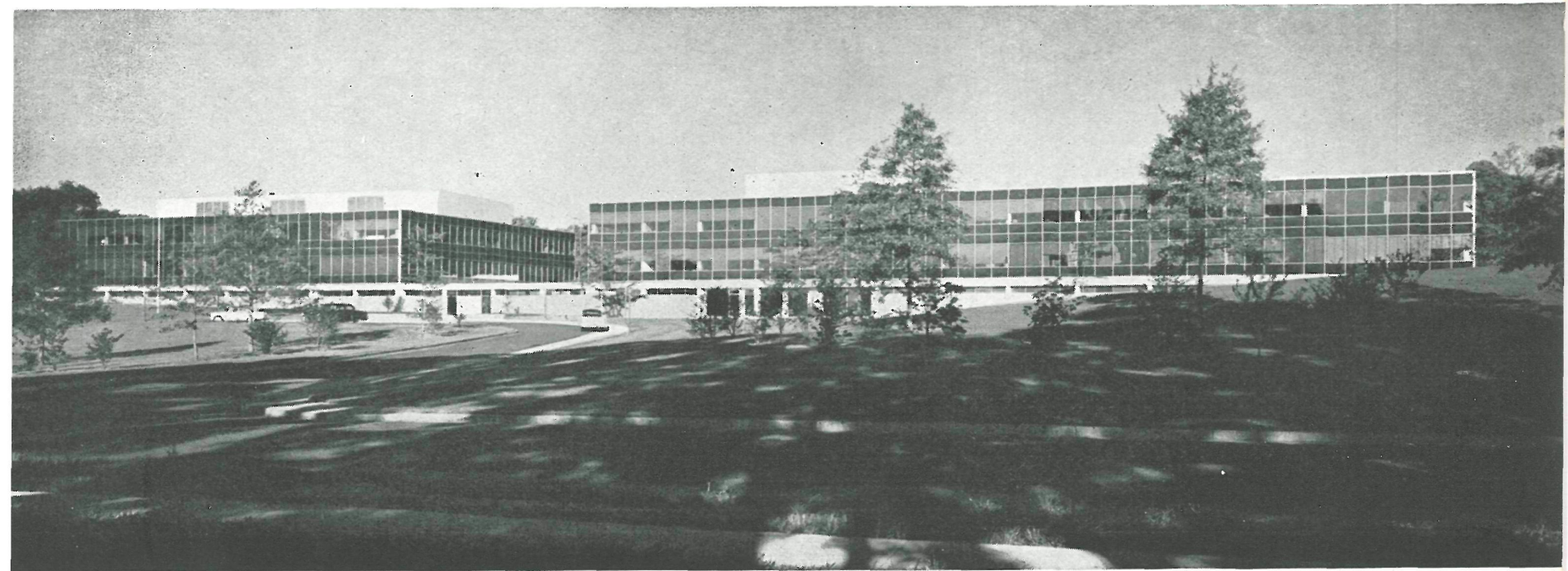

situación 


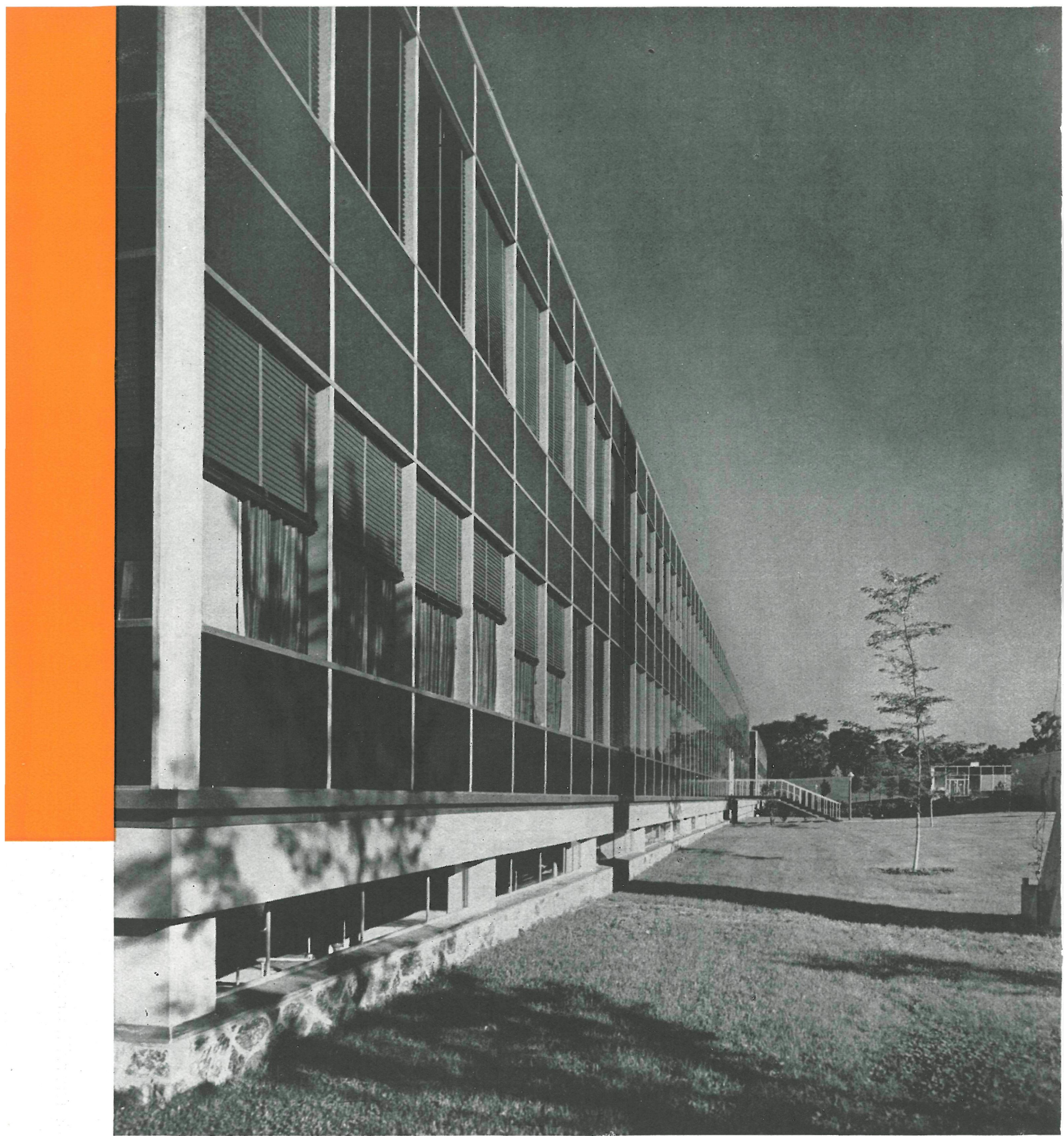

Un laboratorio de productos farmacéuticos, como todo centro de investigación, requiere una labor continua y lenta de enclaustramiento pesado. Ello ha motivado el elegir para estos laboratorios un emplazamiento privilegiado y una casi total transparencia de cerramientos, tratando de comunicar las estancias de trabajo con la verde y sedante naturaleza que rodea todo el edificio. Así, la vista se extiende hacia prados anchurosos y tranquilos tachonados de frondosos árboles.

Con una visión estética cumplida, se ha conseguido que la obra debida a la mano del hombre se complemente y participe en el concierto espontáneo de la naturaleza. 

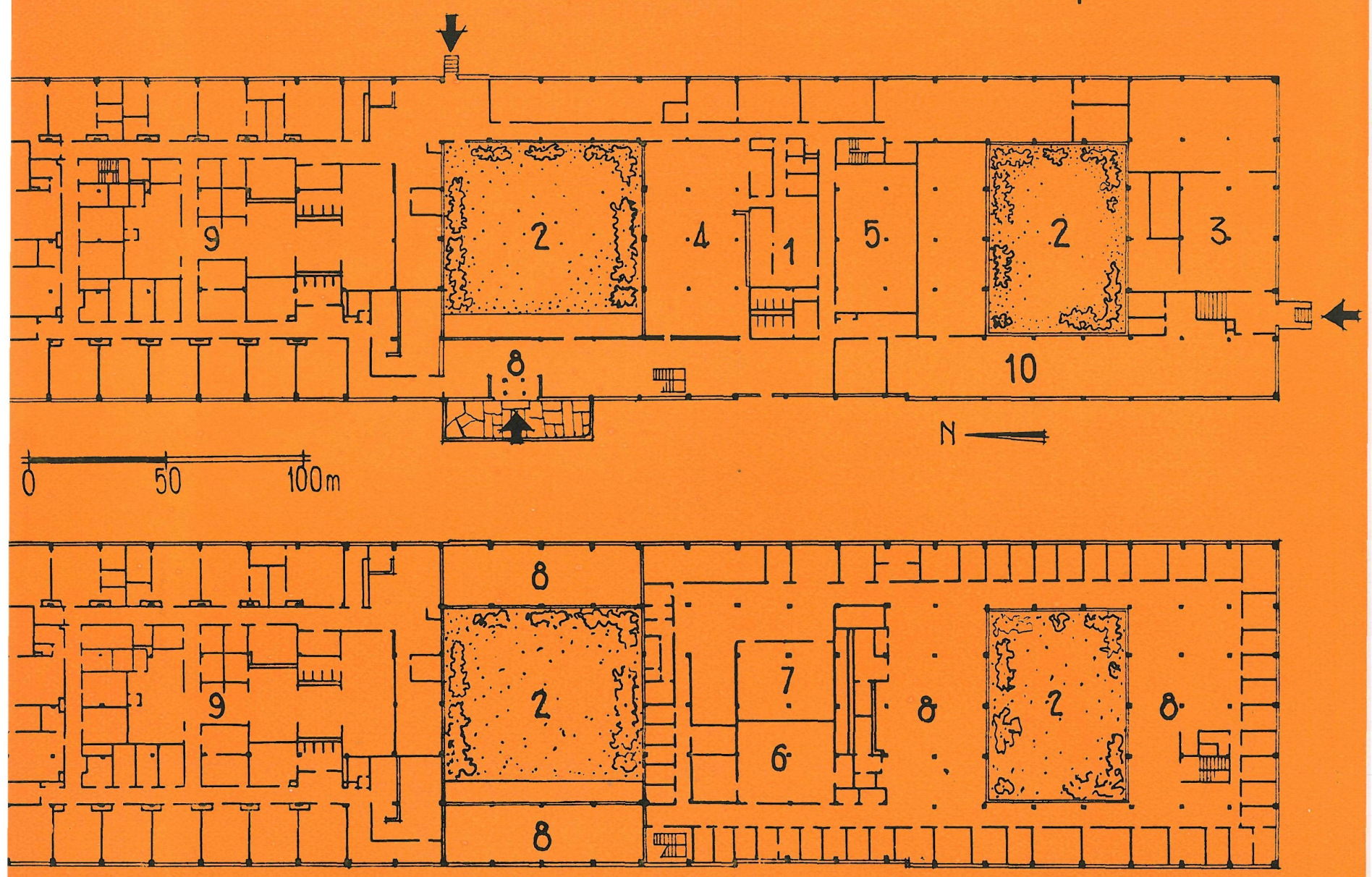

1. Cocina.-2. Patio. - 3. Instalaciones -4. Comedor.-5. Ensayos mecánicos.-6. Biblioteca.-7. Conferencias.-8. Vestíbulos.-9. Laboratorios.-
10. Maquinaria.
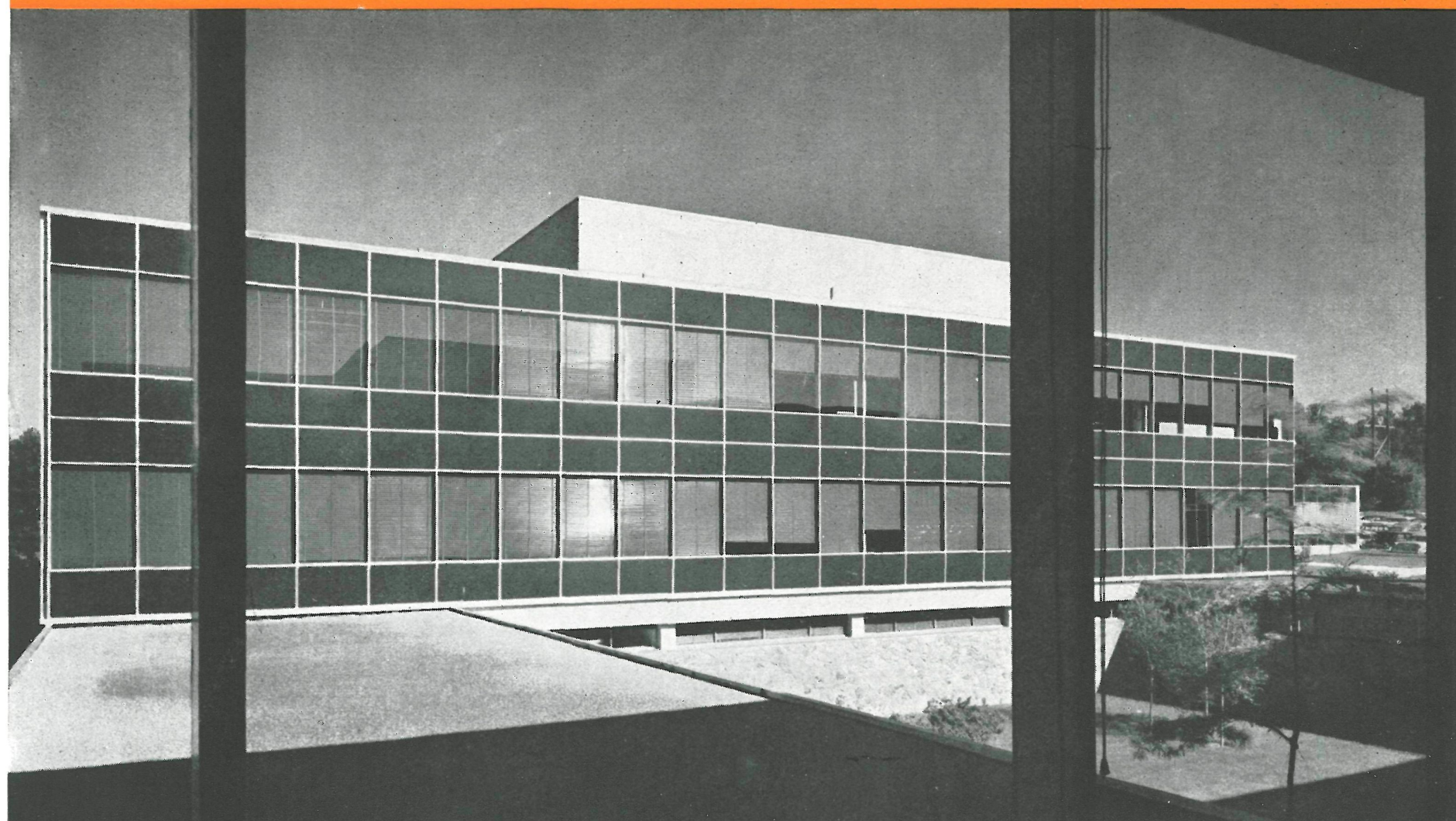


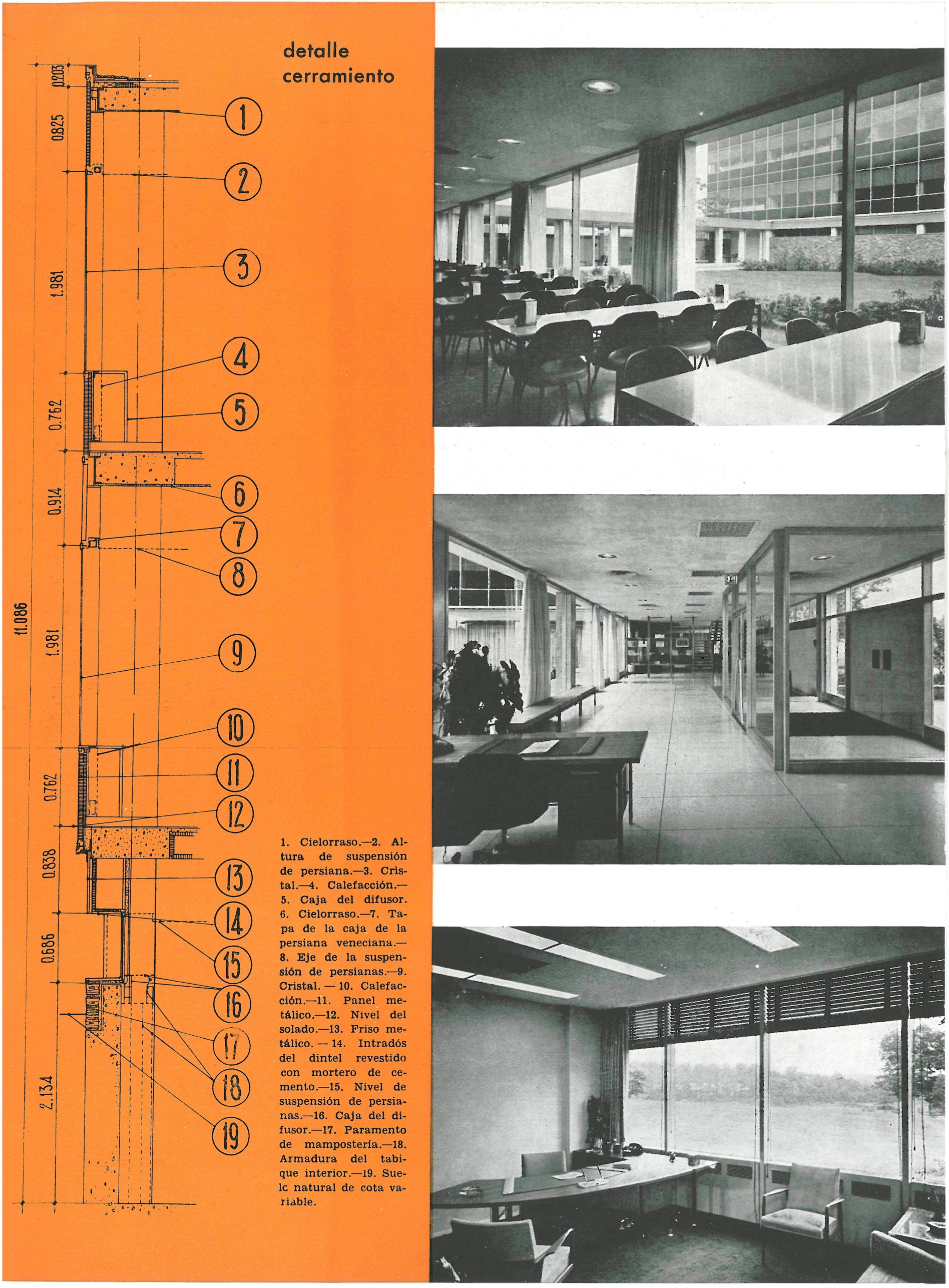




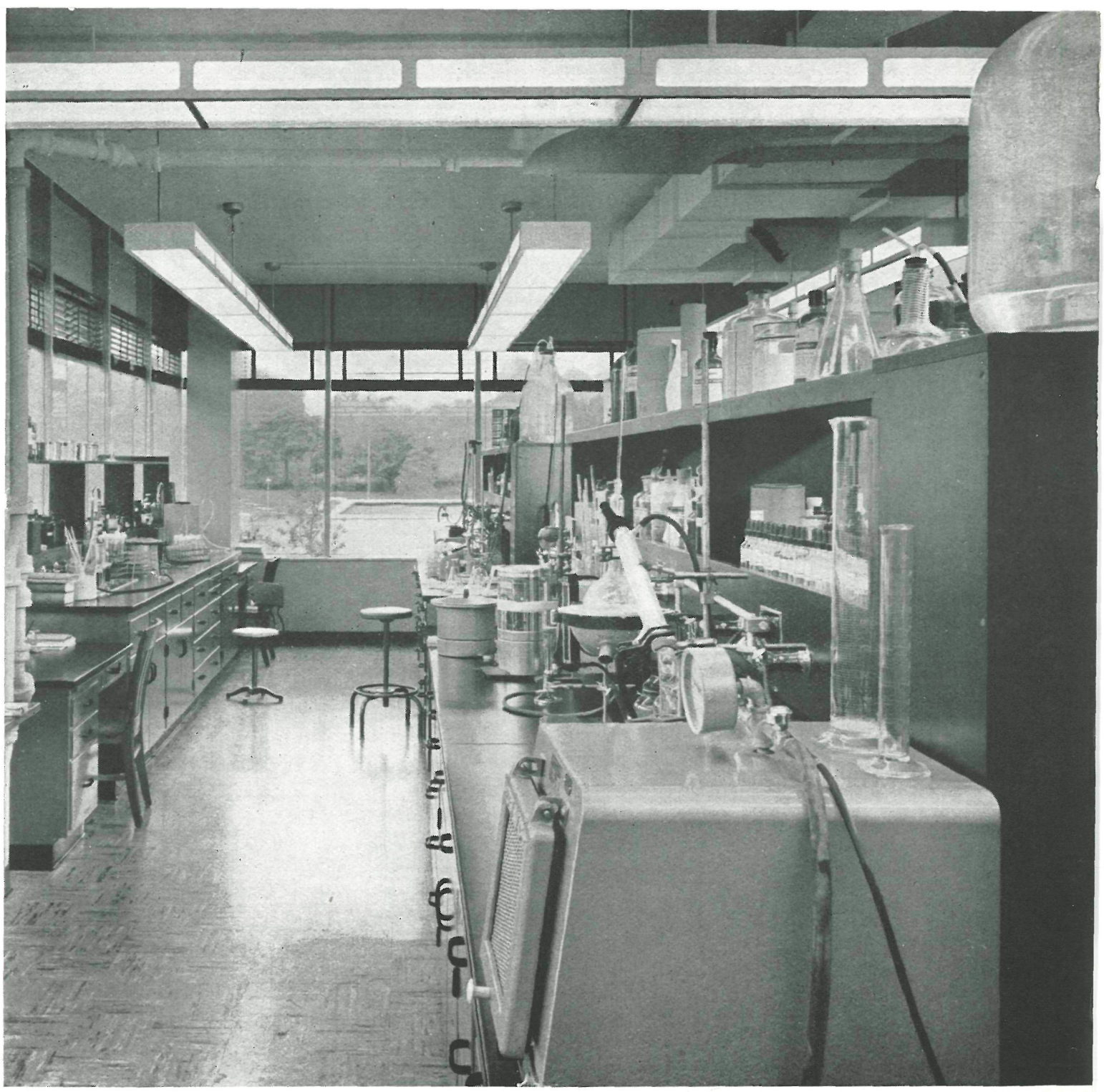

Dos altos bloques-al N. y al S.-ensillan un elemento central bajo. Aquéllos tienen tres alturas con tratamiento exterior uniforme e igual: cristal y paneles de acero cubiertos de porcelana azul verdosa, todo ello colgado de una estructura esbelta de aluminio. El aluminio se deja visto y una banda acusada de acero, pintada de blanco, separa las dos plantas superiores de la inferior, contrastando la textura grácil y etérea de aquéllas con la más pesada de ésta, construída con piedra del país. Para acusar más esta separación con el zócalo, se ha dispuesto una cinta de estrechas ventanas, en horizontal, que dan luz a las dependencias del nivel inferior.

Se ha aprovechado el relieve natural del terreno, que desciende desde una pequeña altura-por la que transcurre la línea del ferrocarril-hasta los laboratorios, para emplear el parque de estacionamiento de vehículos, de modo que los empleados del centro vayan desde sus automóviles hasta el lugar de trabajo, con un breve paseo y con sólo ascender o bajar unos escalones.

La entrada principal es por el cuerpo bajo central, elevándola ligeramente del nivel del suelo, en cuya parte se forma una agradable vaguada alfombrada de césped.

La composición del conjunto se basa en la división marcada de las tres partes fundamentales: laboratorios en el extremo norte; zona noble de recepción en el centro, y oficinas en la parte sur. Dos patios ajardinados alegran las zonas de trabajo y el vestíbulo de entrada. Separado de este bloque principal, se han construído: el laboratolio especial, de fina factura; el almacén, y el laboratorio de hidrogenación. 


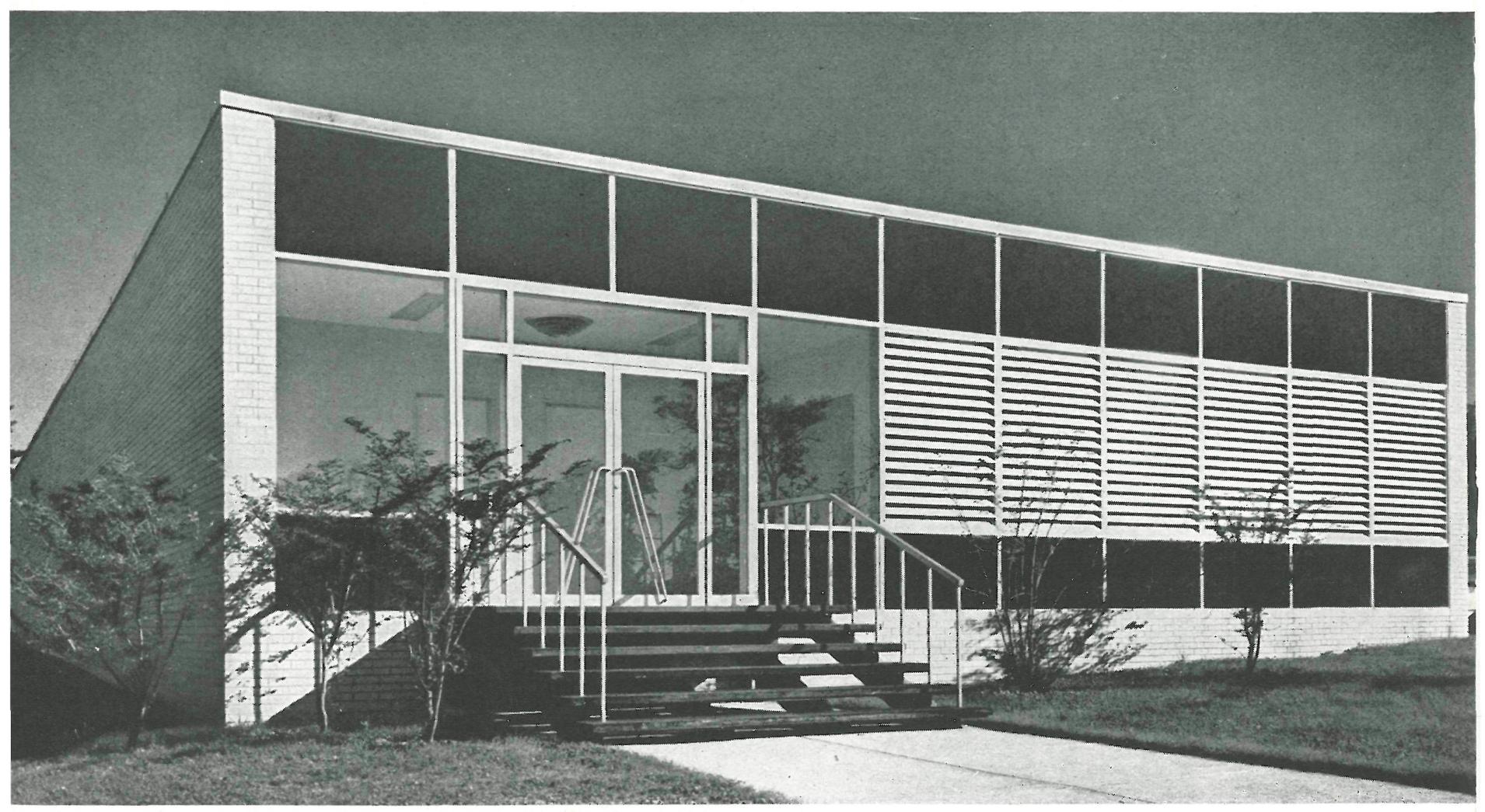

Fotos: EZRA STOLLER

En la parte sur del patio principal se ha situado el comedor de empleados y el hall, adyacentes al vestíbulo principal. Mediante el empleo de paneles acristalados y móviles pueden, en un momento dado, comunicarse diáfanamente las dos estancias, procurando un amplio y espléndido espacio para fiestas. El propio comedor puede ampliarse hacia el patio, en los días de temperatura adecuada.

La firma Wyeth, fundada en el año 1860 como almacén de drogas en Walnut Street, en Filadelfia, ha crecido y progresado rápidamente, siendo, en la actualidad, una casa de primera línea en el campo profesional, con una basta red de filiales y hasta 68 casas afiliadas en diferentes naciones. El programa básico de ésta, su nueva Sede central, comprende una extensión de 70.000 pies cuadrados planta para laboratorios y 80.000 para oficinas, con sus servicios correspondientes.

El problema consistía en crear un edificio digno y dotado con todos los adelantos técnicos, aprovechando la belleza natural del terreno, de 25 acres de extensión. A la perfección de su acondicionamiento-clima artificial, luz fluorescente, instalaciones propias para la investigación...-, hay que añadir la maestría con que ha sido resuelto el tema por sus proyectistas, haciendo de este edificio un ejemplo claro y evidente de las características más acusadas de la Arqujtectura moderna: sinceridad, perfección constructiva y sencillez armónica.

V. $M$. 